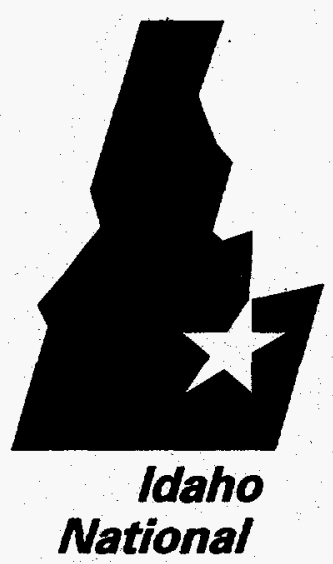

Engineering Laboratory
INEL - 96/0067

March 1996
Independent Review of Design and Analysis for Holtec Spent Fuel Storage Racks of CPP 666 Pool 1
G. K. Miller 
INEL - $96 / 0067$

\title{
INDEPENDENT REVIEW OF DESIGN AND ANALYSIS FOR HOLTEC SPENT FUEL STORAGE RACKS OF CPP 666 POOL 1
}

\author{
G. K. Miller
}

Published March 1996

\section{Idaho National Engineering Laboratory Lockheed Idaho Technologies Company Idaho Falls, Idaho $\mathbf{8 3 4 1 5}$}

Prepared for the

U.S. Department of Energy

Assistant Secretary for Environmental Management

Under DOE Idaho Operations Office

Contract DE-AC07-94D13233 


\section{EXECUTIVE SUMMARY}

This document summarizes the analyses and review performed to develop and validate the design of the new fuel storage racks for the Idaho Chemical Processing Plant (ICPP) Fuel Storage Area (FSA). Holtec International is responsible for the design and fabrication of the storage racks. The structural consulting firm, Advanced Engineering Consultants, was contracted to perform independent review on the design and analysis of the racks. LITCO was involved in facilitating the process of resolving comments that AEC raised in their review. Then, late in the analysis and review effort, scheduling and budget constraints required that LITCO assume responsibility for completion of the independent review. This report describes the issues raised in the review effort and the resolutions to these issues. The conclusion is reached that the review issues for the racks of Pool 1 have been satisfactorily resolved in the final design and analysis for these racks.

Section 1 of this report gives a brief description of the project. Section 2 describes the approach that Holtec used in analyzing the racks and results from these analyses. Section 3 describes the independent review process. Section 4 discusses the identification of and resolution to comments on the design analysis. Section 5 describes additional analysis performed to address major concerns with the Holtec design analysis. Section 6 presents a summary of AEC's independent review, which is based on AEC's final review report. Finally, Section 7 gives the Lockheed Idaho Technologies Company (LITCO) position on the acceptability of Holtec's design.

\section{DISCLAIMER}

\footnotetext{
This report was prepared as an account of work sponsored by an agency of the United States Government. Neither the United States Government nor any agency thereof, nor any of their employees, makes any warranty, express or implied, or assumes any legal liability or responsibility for the accuracy, completeness, or usefulness of any information, apparatus, product, or process disclosed, or represents that its use would not infringe privately owned rights. Reference herein to any specific commercial product, process, or service by trade name, trademark, manufacturer, or otherwise does not necessarily constitute or imply its endorsement, recommendation, or favoring by the United States Government or any agency thereof. The views and opinions of authors expressed herein do not necessarily state or reflect those of the United States Government or any agency thereof.
} 


\section{CONTENTS}

EXECUTIVE SUMMARY $\quad$ ii

1. INTRODUCTION 1

2. HOLTEC DESIGN ANALYSIS APPROACH AND RESULTS 1

2.1 Analysis Approach 1

2.2 Results of Analyses 3

3. PROCESS FOR INDEPENDENT REVIEW OF HOLTEC'S DESIGN ANALYSIS 4

4. IDENTIFICATION OF AND RESOLUTION TO COMMENTS ON HOLTEC'S DESIGN ANALYSIS $\quad 4$

4.1 Review Comments $\quad 4$

4.2 Major Issues $\quad 6$

5. ADDITIONAL ANALYSIS PERFORMED TO ADDRESS MAJOR ISSUES 7

5.1 Holtec Analyses 7

5.2 LITCO Analyses 9

5.3 AEC's Full Pool Analysis Results 9

6. SUMMARY OF AEC'S INDEPENDENT REVIEW EFFORT 11

6.1 Sections 1 and 2 of AEC's Final Review Report 11

6.2 Sections 3 and 4 of AEC's Report 11

6.3 Section 5 of AEC's Report 12

6.4 Section 6 of AEC's Report 13

7. LITCO POSITION ON ACCEPTABILITY OF HOLTEC'S DESIGN 14

$\begin{array}{lll}7.1 & \text { LITCO Comments } & 14\end{array}$

7.2 Assessment of the Review 15

7.3 Adequacy of Holtec's Design Analysis 15

8. REFERENCES 16 


\section{Independent Review of Design and Analysis for Holtec Spent Fuel Storage Racks of CPP 666 Pool 1}

\subsection{INTRODUCTION}

One of the primary missions of the Idaho Chemical Processing Plant (ICPP) is to receive and provide interim storage for spent nuclear fuels in the fuel storage pools in the FAST facility. When fuel processing was discontinued, it was necessary to provide fuel storage racks with greater capacity and different port sizes to accommodate near-term fuel storage requirements. In response to this need, the Fuel Storage Area Reracking (FSARR) project was created.

The FSARR project will rerack Pool 1 of the FSA with 35 stainless steel racks providing 925 10-in. square storage ports nominally $20 \mathrm{ft}$ in height. Pool 5 will be reracked with 21 stainless steel racks and will provide 29416 -in. square storage ports nominally $15 \mathrm{ft}$ in height.

Fluor-Daniel Inc. prepared the procurement specification (Ref. 1) that covers the technical requirements for the design, materials, fabrication, inspection, testing, packaging and delivery of the storage racks, including installation tools, ancillary hardware and lifting fixtures. Holtec International of Cherry Hill, New Jersey was awarded the contract to provide the deliverables noted above. Under subcontract to Holtec, U. S. Tool and Die in Pittsburgh, Pennsylvania, is fabricating the racks.

\subsection{HOLTEC DESIGN ANALYSIS APPROACH AND RESULTS}

\subsection{Analysis Approach}

Holtec International has documented their design analysis for the spent fuel storage racks of Pools 1 and 5 in Reference 2 . This package was originally submitted in December 1994, and a major revision was issued on June 2, 1995. It was issued in final form (relative to the Pool 1 racks) on November 22,1995 . The racks were required to be designed and fabricated in accordance with the procurement specification (Ref. 1). Holtec's final design analysis approach for the racks (after resolution of review comments) of Pool 1 is summarized below. Details of the rack design and analysis can be found in Holtec's analysis report.

There are a total of 35 racks in Pool 1 arranged in a $7 \times 5$ array. Each rack has four pedestals at the bottom, which rest on (but are not fastened to) bearing pads that lie on the pool floor. Each rack is connected to adjacent racks at the top to prevent any rack from overturning and impacting a pool wall. The structural elements that connect the racks to one another are referred to as "interties." There are typically six interties (counting corners) along the side of a rack in Pool 1. Each rack in the assemblage contains either 25 or 30 storage ports arranged in a $5 \times 5$ or $6 \times 5$ array, respectively.

A detailed analysis of an individual rack was performed as a means of determining stress levels throughout the rack structure. The finite element model of the individual rack was still not detailed enough to allow for a complete assessment of important local portions of the rack, namely the intertie regions and the pedestal areas. Thus, these areas were evaluated separately. The analysis of the individual rack produced intertie loads and pedestal loads that were used as input to these analyses of local areas.

Performing an analysis on an individual rack required that an assumption be made as to how the rack interacts (through the interties) with surrounding racks. The basic assumption used was that the 
racks in the pool move in-phase relative to one another. If the racks do indeed move in-phase relative to one another during seismic motion, then the assumption used in the analyses of the individual rack would be correct and no further analyses would be necessary. There is some expectation that the in-phase assumption should produce conservative vertical components for the intertie forces since adjacent sides of adjacent racks would move in opposing vertical directions during in-phase motion. The vertical components of the intertie forces prove to be the most important relative to stresses in the racks. There is the possibility, however, that out-of-phase motion induces dynamic rack response not captured in the single rack analysis. To further assess multi-rack behavior, therefore, a full pool finite element analysis was performed where each rack in the 35-rack array was represented by a simplified model. The racks were linked in the full pool model at the intertie connection locations. Since no assumptions were made concerning rack behavior, the full pool analysis permitted out-of-phase as well as in-phase rack motion. This analysis was used to evaluate displacement of the overall array and to determine whether any of the racks in the pool exhibit unexpected behavior. It was also used to compare intertie loads and pedestal loads with those determined from the individual rack analysis. If these loads were to increase relative to those obtained from the single rack analysis, then the rack stresses would have to be re-evaluated for effects from these modified loads. If the loadings from the full pool analysis were to be less than those of the single rack analysis, it would then be evident that the full pool rack behavior does not include any significant dynamic response not already captured in the single rack analysis. Any such dynamic behavior would be manifested in the form of higher reaction forces. The full pool analysis was also needed to evaluate the effects of pattern loading in the pool, where some racks may be full while others are empty.

The detailed finite element model for an individual rack was developed using the ANSYS 5.1 computer program. The model contained linear elastic elements to represent the basic rack structure, gap interfaces between the rack pedestals and pool liner and between the stored fuel and the port walls, friction between the pedestals and pool liner, fluid coupling between the fuel and port walls and between the racks and surrounding water mass, and spring elements to represent the interties. Similarly, the simplified model for each rack in the full pool analysis incorporated elastic behavior of the rack structure, gap elements to permit rocking and sliding motion of the rack and rattling of fuel within the ports, fluid coupling between the fuel and the port walls and between the rack and surrounding water, and spring elements to represent the interties. The springs representing the interties included tension/compression elements that, because of the in-phase assumption, were not included in the single rack analysis. The full pool model also included gap elements at the bumper locations at the base of the racks to allow for contact between racks. Seismic time histories of 20-sec duration were input simultaneously in three orthogonal directions in both the single rack and full pool analyses. These time histories represented basemat motion as determined from soil-structure analyses performed by AEC, and were provided to Holtec as input for their design analyses.

Holtec's design analysis report identifies several conservative assumptions that were made in the fuel rack analyses that helped to assure that calculated stresses represented bounding levels. One of these assumptions, used in the single rack analysis, was that the wet weight of the fuel was set higher than its actual value (by $24 \%$ ). This higher weight imparted a larger rattling mass to the fuel than would actually occur, resulting in larger displacements and stresses in the single rack analysis. This conservative assumption was used only in the analysis of the single rack; the actual wetted mass was used for the fuel in the full pool analysis. In this respect, then, the single rack analysis was more conservative than the full pool analysis. 


\subsection{Results of Analyses}

Holtec performed analysis for three different time history inputs and for a range of coefficients of friction (from 0.2 to 0.8 ) for both the single rack and full pool analyses. The rack design was based on the most severe responses obtained from all of the cases considered. Results obtained from the single rack analysis as reported by Holtec are listed below:

- The maximum rack displacements calculated were 1.63 in. for the east/west direction and 0.62 in. for the north/south direction. Because of the spacing between the racks and pool walls, the racks do not impact the walls.

- Stresses due to seismic loading in the pedestals, cross bracing, port walls, intertie bolts and plates, pedestal-to-baseplate welds, welds in the intertie regions, and all port-toplate welds meet Level D stress limits of the ASME Code Section III, Division 1, Subsection NF (Ref. 3).

- Stresses due to static loading in the rack structure and pedestals are well within Level A limits of Subsection NF.

Results and conclusions reached from the full pool multi-rack analysis as reported by Holtec are listed below:

- The maximum rack displacements were less than maximum rack displacements obtained from the single rack analysis.

- The pedestal forces were generally enveloped by the maximum pedestal forces obtained from the single rack analysis, though a few isolated cases of moderate exceedance (up to $26 \%$ ) did occur in the vertical component. An assessment of the maximum pedestal force calculated in the full pool analysis indicated that acceptability of rack stresses was not affected.

- The maximum intertie forces were enveloped by the intertie forces obtained from the single rack analysis, except for the introduction of tension/compression forces in the interties caused by out-of-phase motion. The larger vertical intertie force from the single rack analysis was more severe relative to rack stresses than was the combination of vertical and horizontal forces from the full pool analysis.

- Holtec concluded that, because the rack displacements, pedestal forces and intertie loads for the full pool analysis were essentially enveloped by those of the single rack analysis, the single rack analysis represents the basis for design of the racks.

Other results from Holtec's design analyses are:

- Analysis of the deep drop of a fuel container indicated that the baseplate of the rack will not be perforated, nor will the baseplate deflect enough that it would contact the floor. The baseplate is a horizontal plate located at the bottom of the racks, which is welded to both the pedestals and the ports. If the fuel container is dropped over a pedestal, results indicate that there would be local damage to concrete directly beneath the pool liner, but the liner will not permit leakage.

- Analysis of a shallow drop of a fuel container onto the top of a port wall indicated that the port lid would not be perforated and that the level of deformation in the port wall and lid is acceptable.

- Analysis of a criticality barrier indicated that the barrier deformation would not permit a fuel container to fall to the floor slab in the space between the racks and pool wall. 
- An analysis for a 4000-1b uplift load applied either vertically or at a $45^{\circ}$ showed that this load did not cause stresses large enough to encroach on the designated neutron flux gap.

\subsection{PROCESS FOR INDEPENDENT REVIEW OF HOLTEC'S DESIGN ANALYSIS}

An independent review of Holtec's design and analysis for the spent fuel storage racks was conducted in accordance with the scope of work for this review (Ref. 4). The scope of work required that the review be performed in accordance with the quality assurance requirements of ASME/ANSI NQA-1 (Ref. 5), and that the review be detailed enough to assure that the technical requirements of the procurement specification (Ref. 1) have been met. The scope of work specified that the following activities be conducted:

- Determine that analysis inputs are adequately documented and used appropriately.

- Determine that assumptions are adequately documented and justified.

- Determine that applicable codes and standards are identified and used appropriately.

- Determine that appropriate analysis methods are used and implemented correctly.

- Determine whether analysis output is reasonable compared to the analysis inputs and other similar analysis (i. e. independent calculations).

- Determine whether the analysis output has been appropriately applied to the design of the racks.

The structural engineering consulting firm Advanced Engineering Consultants (AEC) was contracted to perform the independent review in January 1994. As discussed below, AEC generated numerous technical comments in their review. Many of these comments were reflective of the review requirements listed above. In March 1995, LITCO became involved in facilitating the resolution to AEC's comments. In this process, LITCO became well acquainted with the analysis package and provided input for its improvement. Due to scheduling and cost restraints, LITCO assumed the independent review effort late in the design process (August 1995). By this time, AEC had participated in the resolution to a majority of their review comments. In assuming the independent review, LITCO assured that all outstanding AEC review issues were resolved in accordance with project requirements.

\subsection{IDENTIFICATION OF AND RESOLUTION OF COMMENTS ON HOLTEC'S DESIGN ANALYSIS}

\subsection{Review Comments}

In the independent review, comments were raised on Holtec's design analysis package in two phases. A first set of comments was written after Holtec issued the original version of the analysis report (December 1994). These comments were presented in letters from W. O. Crownover, Subcontract Administrator for LITCO, to Holtec International, dated February 14, 1995 and March 21, 1995 (Refs. 6 and 7). The former letter contained preliminary comments prepared by AEC. The latter contained comments prepared by AEC and by LITCO. Comments by AEC in the letter of March 21 supplemented and in some cases reiterated comments of the previous letter. A second set of comments was generated after the report was revised (June 1995), as will be discussed later.

The comments prepared by LITCO in the March 21 letter primarily identified shortcomings with the quality and completeness of documentation in the original version of the report. The comments 
noted numerous specific portions of the report where further information should be supplied. These deficiencies in information were corrected where appropriate in later revisions to the report. The result of these comments was that the report was expanded significantly with the presentation of more detailed information. LITCO comments of a technical nature in the March 21 letter were addressed and satisfactorily resolved in subsequent revisions to the report.

A number of the AEC comments in the February 14 and March 21 letters pertained to application of ASME Code Subsection NF acceptance criteria. These comments were addressed in the subsequent revisions to Holtec's analysis report. Other comments concerned possible modeling problems in Holtec's analysis. Of these, several comments required modifications to Holtec's finite element models that were incorporated in subsequent analyses.

One of AEC's comments pertained to an accidental deep drop of a fuel container to the bottom of a corner port of a rack. The comment was that the impact load would be taken by a single rack pedestal directly beneath the load. Because the rack pedestal is a very rigid element, this inevitably meant that the impact load for a corner drop would impart some local damage to the concrete below. ICPP operations personnel stated that this was acceptable provided that the liner between the pedestal and floor was not ruptured. Holtec performed a calculation on the liner, in which they assumed the impact load to be resisted by shear stress in the liner combined with bearing stress in the concrete beneath the pedestal. Holtec concluded that the deflection of the liner was small enough that it would not permit leakage. Because Holtec did not assess strain levels in the liner, though, their calculation did not assure that the liner would not rupture. AEC subsequently performed a calculation where they evaluated strain levels in the liner assuming cratering of the concrete beneath the pedestal. They assumed that the liner deformed to accomodate the shape of the crater. AEC determined that strain levels were small enough $(<1 \%)$ that the liner would not rupture. All parties (AEC, Holtec, and LIT$\mathrm{CO})$ concurred that damage to the concrete was local, and this became a closed issue.

It is noted that, as of the original report, Holtec had not performed a full pool analysis. Among the issues raised by AEC on the original analysis report, three of the more significant concerns relating to Holtec's analysis approach were (1) the in-phase assumption used in the single rack analysis did not meet the requirement of the Procurement Specification that out-of-phase motion be considered, (2) the model did not adequately represent the behavior of the side and corner racks, and (3) a single rack model cannot represent the effect of pattern loading in the pool. To address these issues, Holtec later performed an analysis of the full 35-rack array of Pool 1 using a simplified model for each rack in the array. The purpose for the analysis was to evaluate behavior of the assemblage of racks for the effects of out-of-phase motion, differences in behavior between outer and interior racks, and the effects of pattern loading in the pool. The plan was to modify or scale the loadings of the single rack analysis if the full pool analysis showed that the loadings on any of the racks increased. Results from the full pool analysis were reported in the first revision to Holtec's analysis report. The general indications were that the full pool behavior did not adversely affect the rack design loadings determined from the single rack analysis.

Holtec's full pool model included the basic characteristics of the full pool dynamic behavior, but lacked a potentially important aspect of rack motion. This was that the individual racks in the full pool model were treated as rigid bodies, which meant that the contribution from flexural or torsional modes of vibration in the individual racks was not truly represented. To compensate for this lack of flexibility, Holtec reduced the intertie stiffnesses in the model so that overall rack displacements basically matched those of the single rack analysis. Holtec regarded the full pool analysis to be a confirmatory evaluation of the single rack analysis, and considered the full pool model sufficient 
to represent the global rack behavior. The approach, though, was not considered to be acceptable by LITCO or AEC. AEC continued to raise these concerns after the first revision to Holtec's report was issued and performed an independent full pool analysis to evaluate global rack behavior. They selected the racks of Pool 5 for this analysis since that pool contains only 21 racks. Results of AEC's full pool analyses are discussed in Section 5.3. Holtec performed a modified full pool analysis for the Pool 1 racks, which is described in Section 5.1.

The comments on the original version of the report were addressed (though not all satisfactorily resolved) in a first revision to the report. Several comments that were not resolved to AEC's satisfaction in the first revision and new comments identified after the first revision were presented by AEC on LITCO Form 5733, "Review Record Form" (Ref. 8). AEC wrote 14 comments on Form 5733. The resolution to these issues was among topics discussed in a meeting held at AEC's offices on July 21, 1995, which was attended by AEC, Holtec, and LITCO. During the meeting, these comments (except for one significant item discussed in Section 4.2) were either resolved or specific actions were identified to resolve the comments. Some of these comments had to be resolved by making corrections in analyses that Holtec performed after the meeting. It is noted that three of these comments were directed specifically to racks of Pool 5 . Holtec provided written responses to the 14 comments, which are contained in the project records. Based on verbal and written communications, reanalyses performed, and changes to the report, all comments (as they applied to Pool 1) were resolved as of the final report.

Because AEC was not involved to the end of the independent review, they did not witness the final resolution to all of these issues. LITCO did investigate each issue (relative to Pool 1) and concurred with the final resolutions.

\subsection{Major Issues}

In the July-August 1995 timeframe, AEC also identified what they deemed to be five major concerns with the design analysis based on their review and independent analysis efforts. These comments were discussed verbally in meetings held during this time. Only one of these major concerns (Item 3 below) was among the comments recorded on Form 5733. The five major concerns are described below:

1. The full pool behavior of the rack array for Pool 5 showed that the racks exhibit out-ofphase behavior. Holtec made the assumption that the racks move in-phase in their detailed single rack analysis. AEC was concerned that the single rack analysis cannot treat out-ofphase motion.

2. AEC's full pool analysis at the time showed that outer racks exhibit unstable behavior in the form of lifting and rotating outward. If this proved to be a problem, restraints at the base of the outer racks could be required to prevent this type of rack behavior. If restraints were installed, additional analysis could be needed to assess the effects of these restraints on the racks and the pool wall.

3. Holtec had performed their single rack analyses using a single input time history for each load case, whereas the Procurement Specification had specified that three time histories be used in the calculations. Holtec had presented a justification for selecting one time history as a controlling input for each load case considered. AEC questioned the validity of the justification and reran Holtec's model of a $6 \times 5$ rack for several time history sets with coefficients of friction of 0.8 and 0.2 . AEC's results showed that TH-1 (time history one) controlled the shear force in the pedestal and vertical force in the interties, and that $\mathrm{TH}-2$ controlled the 
maximum displacement at the top and bottom of the rack. Their conclusion was that one time history does not control design of a rack.

4. AEC did not concur with Holtec's modeling approach for the side and corner racks. They questioned whether a model for an interior rack could be used to represent the behavior of an outer rack.

5. AEC performed hand calculations that showed overstresses in welds and plates in the region of intertie connections (intermediate and corner). These results conflicted with calculations performed by Holtec, which indicated that these components were in accordance with acceptance criteria. AEC's stresses were based on more restrictive load paths than were assumed by Holtec. AEC also calculated overstresses in the intertie plates and bolts caused by prying action. AEC acknowledged that their approach to the intertie plates and bolts was conservative and that a more detailed analysis would likely show that these plates and bolts are adequate. LITCO felt that a detailed analysis on these portions of the design was warranted to determine whether they meet ASME Section III Subsection NF criteria. If Code criteria could not be met, appropriate modifications to the design would be needed.

LITCO presented these issues to Holtec in a meeting held on August 22, 1996, to develop a plan to reach appropriate resolutions. It was agreed that Holtec would perform additional analysis to address the first four issues. LITCO addressed the fifth issue by performing detailed assessments of the intertie plates, bolts, and connection areas. The following section discusses in greater detail the additional analyses performed.

\subsection{ADDITIONAL ANALYSIS PERFORMED TO ADDRESS MAJOR ISSUES}

As discussed in Section 4, resolution to the five major issues was based on performance of additional analyses. Some of this analysis was performed by Holtec, while other analysis was conducted by LITCO. The additional analyses performed to address the major review concerns are described below. Items 1 through 5 below correspond to the same item numbers of Section 4 .

\subsection{Holtec Analyses}

1. Holtec performed a new full pool analysis for the 35 racks of Pool 1 to determine the effects of any out-of-phase behavior among the racks. Racks were assessed for effects on intertie loads, pedestal loads, and rack stresses. Racks were also assessed for displacement of the overall array. The full pool analysis employed simplified models for each of the racks in the array. The new model for each rack used a three-dimensional beam element to represent the rack body, which incorporated flexural and torsional flexibilities in these racks. It also included gap elements and friction spring elements at the rack base to permit rocking and sliding motion, gap elements to permit rattling fuel, gap elements at bumper locations at the base of the racks to capture potential contact between bumpers, spring elements to represent interties, and hydrodynamic coupling to represent hydrodynamic effects of rack-to-fuel fluid motion, fluid motion between ports within the rack, and fluid motion under the baseplate of the rack. A total of 14 full pool cases were performed to study effects from different time history inputs, variations in friction coefficients, differing pattern loads, and altering the solution time step size. 
Results: The results of the full pool analyses showed that, though there is some out-ofphase behavior, this behavior is inconsequential relative to the loading of the racks. The maximum intertie forces and rack displacements were exceeded for all load cases by those obtained from the bounding detailed single rack analysis, except that out-of-phase behavior introduced an axial force in the intertie plates. The combination of an axial force with the maximum vertical intertie force obtained from the full pool analysis was analyzed in detailed assessments of the intertie connection regions performed by LITCO (Item 5 below). This case proved to be less severe than the application of the maximum vertical intertie force obtained from the single rack analysis.

In their full pool analyses, Holtec identified isolated cases where pedestal vertical loads exceeded the maximum value obtained from single rack analysis. The maximum load determined was $80700 \mathrm{lb}$ in a corner rack (vs. a $64099 \mathrm{lb}$ maximum for the single rack analysis). The shear force at this location (13873 lb), though, was much less than the shear force used in the single rack design basis $(48599 \mathrm{lb})$. Holtec determined that stresses in the pedestal and pedestal-to-baseplate weld were acceptable for the maximum full pool pedestal load, considering combined vertical plus shear forces. Since the loadings obtained from the single rack analysis (which were used as the basis for design) essentially envelop those from the full pool analysis, out-of-phase motion occurring in the full pool analysis does not adversely affect the rack design.

Holtec's full pool results showed that maximum displacements occurred in the case where all racks are full and the coefficient of friction is 0.2 . No load case clearly controlled the intertie and pedestal loading.

2. The full pool analysis was used to examine the behavior of outer racks to determine whether instabilities occur.

Results: The analyses showed that the outer racks do not exhibit unstable behavior. Subsequent full pool analysis by AEC (discussed in Section 5.3) on the racks of Pool 5 also indicated that the outer racks in that pool do not exhibit unstable behavior. Therefore, there is no need to install restraints at the base of the racks.

3. Holtec reran their detailed single rack analyses using all three time histories for full racks and friction coefficients of 0.8 and 0.2 . The cases of partially full racks were not run for all time histories since the case of a full rack was governing (Ref. 2, Chap. 9). Full pool analyses were also run for the three time histories for varying coefficients of friction.

Results: The design loads acting on a rack were obtained from the time history runs that produced maximum loadings on the individual rack. Maximum displacements were obtained from time history runs that produced maximum displacements. The loads and displacements obtained from the full pool analyses were generally enveloped by these design values, again considering all three time histories in the full pool analyses.

4. The full pool analysis was used to examine behavior of the outer racks to determine whether loadings and displacements for these racks differ significantly from loadings on interior racks.

Results: The loadings and displacements obtained for outer racks in the full pool analysis 
were generally enveloped by the design loads and displacements of the single rack analysis. An exception was in the maximum vertical pedestal force, which is addressed in Item 1 above. Outer racks do not experience intertie loading on all sides. This would tend to reduce stresses in the outer racks relative to interior racks, provided that the outer racks do not impact the pool wall.

\subsection{LITCO Analyses}

5. LITCO performed detailed finite element analysis on the intertie plates, intertie bolts, and on the welds and plates in the region of the intertie connections. Intertie connections situated at both the corner and along the side of a rack were modeled in the analyses. The purpose of these analyses was to determine whether stresses in these components meet acceptance criteria of the ASME Code Section III Subsection NF. The approach was to utilize the provisions of the Code before recommending modifications to the design. This analysis is documented in Ref. 9.

Results: An elastic analysis of the intertie plates and bolts showed that the stresses in these components meet the Level D criteria of Subsection NF (which refers to Appendix F for Level D criteria). Results of analyses on the intertie connection areas showed that when elastic analyses were performed, there were portions of each model where the calculated stresses exceeded NF criteria for elastic analysis. For this reason, each model was analyzed by plastic analysis. The plastic analysis accounted for some softening of the prying action on a seismic block due to plastic deformation in the intertie plate. Results showed that the stresses in each model meet NF stress criteria for primary stresses for plastic analysis. Appendix F only specifies stress limits for primary stresses, stating that peak stresses need not be evaluated. The Code does not specifically impose strain criteria for plastic analysis other than what is given by project design specifications. In this case, the design specifications do not provide strain criteria.

The LITCO analyses on intertie plates, bolts, and connection areas were independently reviewed within the LITCO organization. The results of that review are presented in a letter dated December 22, 1995 (Ref. 10). That letter made recommendations relative to the presentation of stress criteria and stress results, which were incorporated in the final report.

\subsection{AEC's Full Pool Analysis Results}

At the time that AEC identified the five major issues discussed above, they had not completed their full pool analysis on the racks of Pool 5. Thus, results attained at that time were preliminary. AEC reported some of their final results in a telefax dated September 27, 1995 (Ref. 11) and also in their final review report (Ref. 12), which is discussed in Section 6. The essentials of those results are described below.

Several of AEC's results from their Pool 5 analysis are similar to results obtained from Holtec's Pool 1 analysis, such as:

- AEC's final analysis showed that there was incipient uplift in a rack pedestal, but there was no instability related to rotation of an outer rack. Holtec's analyses also showed no instabilities in rack behavior. This relieves the concern raised in the second major review issue identified above. 
- In AEC's full pool analysis, the bumpers at the bottom of the racks did not contact. In Holtec's Pool 1 full pool analysis, some bumpers experienced mild contact (less than $2000 \mathrm{lb}$ force).

- AEC determined in their full pool analysis that a single time history did not control the entire design. Holtec concurred with this in the final design, and performed both their single rack and full pool analyses using all three specified time histories.

AEC observed significant out-of-phase behavior in their Pool 5 analysis based on top and bottom rack displacements and axial forces in the interties. Holtec also observed out-of-phase behavior in their analysis of Pool 1, though perhaps not to as great a degree. As discussed above, the out-ofphase behavior that occurred in Holtec's analysis did not adversely affect the acceptability of rack stress levels.

In AEC's full pool analyses, the case where all racks in the pool were full of fuel produced the most severe rack loadings, while the case where one-quarter of the racks were full (while the rest were empty) controlled maximum displacements due to sliding. This is somewhat different from Holtec's results, which showed that no load case clearly controlled the rack loadings and that the case where all racks were full gave maximum displacements. There are 21 racks in Pool 5 vs. 35 racks in Pool 1 , and the racks of Pool 5 are shorter and heavier (when full) than those of Pool 1. These physical differences can be expected to cause some differences in rack behavior between the two pools.

AEC also reported higher intertie forces from their Pool 5 analysis when compared to a corresponding Holtec Pool 5 single rack analysis. This trend is different from Holtec's results for Pool 1, where the intertie forces from the full pool and single rack analyses were of similar magnitude. This difference in trend may be partly due to a difference in the number of intertie locations between AEC's and Holtec's models. AEC's full pool model had a single intertie located at each rack corner, for a total of four interties per rack. Holtec's models (full pool and single rack) had two interties straddling each rack corner, for a total of eight interties per rack. This difference in the number of interties could affect the model behavior, consequently affecting the magnitude of forces calculated for the interties. Further, unless AEC either resolved or combined Holtec's intertie forces in a manner to be consistent with their corner interties, their comparisons with Holtec's results are not particularly meaningful. Again, the physical differences in the racks for the two pools can also contribute to differences in rack behavior.

AEC reported that pedestal impact forces and shears were maximum at corner racks and significantly larger than those from corresponding single rack analysis. Holtec's analysis showed that their maximum vertical pedestal force also occurred at a corner rack, though the magnitude of this maximum force was only moderately greater than obtained from single rack analysis. This difference in Holtec's corner rack pedestal forces would have been more significant had their single rack analysis been based on the actual wetted fuel mass. As stated in Section 2, their single rack analysis used an artificially high fuel mass. The moderate increase in the pedestal force from the full pool analysis did not adversely affect acceptability of rack stresses. A general result from Holtec's full pool analysis for Pool 1 was that the level of loading experienced by all racks was similar in magnitude to that determined from the single rack analysis. The results for Pool 5 will be assessed in forthcoming review efforts. 


\subsection{SUMMARY OF AEC'S INDEPENDENT REVIEW EFFORT}

The structural consulting firm, AEC, was authorized to proceed with independent review of the Holtec spent fuel storage racks on March 14, 1994. They served as the independent reviewer until August 1995, when LITCO assumed the remaining review effort. In their review, AEC generated numerous review comments and performed independent calculations. Because they did not complete the review, AEC did not witness the final resolution to a number of their comments. They have submitted a report that summarizes their entire review effort (Ref. 12) together with all calculations performed. The report focuses primarily on review issues that were relevant at the time that they ceased review efforts (August 1995). AEC indicates in their report that a number of review issues were closed by that time. The issues that AEC identifies as still open at the time their review effort stopped were resolved in the final design and analysis. These latter issues are discussed below according to the section in which they appear.

\subsection{Sections 1 and 2 of AEC's Final Review Report}

In Section 1 (and later in Section 4) of their report, AEC discusses baseline correction of the acceleration time histories. They indicate that the 50-second time histories provided to Holtec as input to their analyses were baseline corrected. With approval from Westinghouse Idaho Nuclear Company, Inc. (WINCO) and AEC, Holtec extracted 20 seconds of input motion from these 50-second time histories to perform their analyses. AEC showed that the 20 -second period selected for analysis meets several acceptance criteria but still allows for some baseline drift in the associated displacement time history. AEC also expressed the opinion that this drift should not significantly affect results of the nonlinear dynamic analysis. In June 1995, Holtec investigated this concern by performing additional single rack analyses (Ref. 13). They re-analyzed a $6 \times 5$ rack of Pool 1 (previously analyzed for a 20 -second time history) for a full 50 -second time history, considering friction coefficients of 0.2 and 0.8 . The analyses for 20-second and 50-second time histories were identical in all other respects. Results of these analyses showed that, with the 20-second extracted time history, pedestal forces were underestimated by up to $6 \%$ while intertie forces were overestimated by up to $13.5 \%$. Meanwhile, rack displacements were actually overestimated with the 20 -second time history. Thus, results for the 20-second time history were either conservative or were close enough to results for the 50-second case that safety margins would not be challenged.

In Section 2 of their report, AEC mentions several review issues relating to design criteria. Resolutions to these were agreed to in the July 21, 1995, meeting mentioned in Section 4.1 of this report, and were resolved as of final issue of Holtec's report.

\subsection{Sections 3 and 4 of AEC's Report}

Section 3 of AEC's report discusses an evaluation of the pool floor liner for potential rupture due to an accidental drop of fuel into a corner port. It was acknowledged by all parties that, at the energy levels calculated, the dropped fuel would impart some local damage to the concrete beneath the rack pedestal. The question becomes whether the pool liner will rupture in this event. Holtec performed a calculation where the impact force was resisted by a combination of shear stress in the liner and bearing stress in the concrete of the pool floor. They concluded that the liner plate does not deflect enough to permit leakage. A shortcoming of Holtec's calculation is that it does not assess the strain levels in the liner, and therefore does not positively assure that the liner would not rupture. AEC performed an independent calculation, accounting for the deformed shape of the liner and determining the associated strain level. The resulting strain in the liner was shown to be small relative to an ultimate strain for the material. 
Section 4 of AEC's report discusses Holtec's selection of a single governing input acceleration time history for the Pool 1 racks, concluding that no single history governs the design in all respects. This is a major issue (referred to as item 3) discussed in Sections 4.2 and 5.1 above, which was resolved by having Holtec perform analyses for all three time histories. The results of these analyses are contained in Holtec's final report.

\subsection{Section 5 of AEC's Report}

Section 5 of AEC's report identifies a concern with Holtec's use in their model of an increased stiffness for the middle and top horizontal plates of the racks. Holtec had increased these stiffnesses in their model, recognizing that the plates were modeled continuously to the port centerlines rather than with openings for the ports. This increase in stiffness was intended to represent the effective stiffness of the plates in bending and shear, since the actual plate spans are shorter than modeled. At the same time, though, this artificially increases the membrane stiffness of the plates. This is likely to have minimal effect on the global behavior of the rack model, since there is little deformation in the plane of these plates whether the smaller or larger value for stiffness is used. As noted by AEC, there could be an effect on stresses in the plates. However, stresses in the top plate were evaluated in LITCO's detailed analyses of the highly loaded intertie connection regions. The models developed for these analyses accounted for the presence of the openings in the top plate, and utilized actual plate stiffnesses. Results of these analyses showed that stresses in the top plate were acceptable. The middle plate is of equal thickness and would experience lesser loading than the top plate, so is also acceptable.

In Section 5, AEC identifies a concern with the treatment of rack-to-basemat hydrodynamic coupling. In Holtec's model, the hydrodynamic elements from rack to basemat represent coupling between adjacent racks or between racks and the surrounding walls. AEC notes that racks moving inphase would experience no hydrodyamic coupling between modules. This would be true except that the racks are surrounded by the pool walls. The squeezing of water between racks and the walls has, in principle, some hydrodynamic effect on all racks since the racks are connected by the interties. The hydrodyamic elements in Holtec's model simulate a rack-to-wall gap, not a rack-to-rack gap. Therefore, Holtec's simulation is not unreasonable. Because the rack-to-wall gap is rather large, this hydrodynamic effect is minimal for these racks.

Section 5 of AEC's report indicates the intermediate interties will not carry a significant lateral shear load. This was recognized in the final analysis, where all of this shear load was assumed to be carried by the corner interties.

In Section 5, AEC indicates that Holtec's whole pool analysis did not include flexibility in the individual rack modules, and that "fuel mass and support stiffnesses are arbitrary." AEC is referring here to Holtec's initial whole pool analysis. In that analysis, Holtec had used a larger fuel mass than actual (as was done in the single rack analyses) and had adjusted the intertie stiffnesses to compensate for the lack of flexibility in the individual racks. This adjustment was intended to gain a basic match in calculated rack displacements for the single rack and whole pool models. Though Holtec believed that the initial whole pool model was sufficient for its purpose, they performed a second whole pool analysis, which incorporated flexural and torsional flexibilities for individual rack models and used actual intertie stiffnesses and fuel masses. Results of the second whole pool analysis are presented in Holtec's final report and are discussed in Section 5.1 above.

In Section 5 of their report, AEC also expresses concerns with the in-phase motion assumption used in Holtec's single rack analysis. They note that whole pool analyses conducted by Holtec (on Pool 1) and AEC (on Pool 5) showed out-of-phase behavior among the rack modules. This is a major 
issue (referred to as item 1) discussed in Sections 4.2 and 5.1 above, which was addressed in Holtec's second whole pool analysis. This second pool analysis was not intended to demonstrate that the racks do not exhibit any out-of-phase behavior. It was intended to assess the effects that out-ofphase motion or other aspects of whole pool rack behavior may have on rack loadings relative to those of the single rack design basis analysis. Other aspects of whole pool behavior considered include pattern loading (where some racks are full while others are empty) and potential differences in behavior of outer racks vs. interior racks. The effects of whole pool behavior were evaluated and are discussed in Section 5 above.

Finally, Section 5 of AEC's report presents results of their whole pool analysis on the racks of Pool 5. Implications of these results are discussed in Section 5.3 (above) of this report.

\subsection{Section 6 of AEC's Report}

Section 6 of AEC's report notes a concern with Holtec's modeling of the connection of cross braces to the port walls in the single rack analysis. In the model, the braces were connected to the ports at the port centerlines, which does not account for the offset between the centerline and port wall. Thus, there could some local torsion imposed on the port section that is not captured in the analysis. These effects are considered secondary in a Subsection NF analysis for frame-type structures, and should be accounted for in the stress limits imposed. Further, there is conservatism in modeling the braces at the port centerline rather than in their true locations. Their true locations would increase the outer dimensions of the rack cross section from what was modeled. The further these braces are situated from the rack centerline, the greater should be the rigidity of the rack structure.

Section 6 briefly discusses Holtec's fatigue evaluation for the racks. To address fatigue requirements, Holtec performed a detailed evaluation of stresses in the pedestal-to-baseplate region. The calculated peak stress intensity range was amplified by a factor of 2.25 to bound other locations in the rack. AEC notes that a basis was not provided for selection of an amplifier of 2.25. LITCO acknowledges that the factor of 2.25 is arbitrary. LITCO also recognizes, though, that there is ample safety margin in the calculated usage factor $(0.41)$, and believes that the work required to determine peak stresses at all locations in the rack is not warranted. When seismic loads are the only source of cyclic loading, as is the case for these racks, a fatigue analysis is not typically even required.

Section 6 of AEC's report also expresses their concern about potential overstresses in plates and welds of the racks, particularly those in the area of the intertie connections. In these areas, the prying action on the bolts tends to amplify the loading exerted on the rack structure. Hand calculations performed by AEC indicated that stresses in some of the plates and welds in both intermediate and corner intertie locations exceeded allowable values. This is a major issue (referred to as Item 5) discussed in Sections 4.2 and 5.2 above. Calculations previously performed by Holtec had shown the weld stresses in these areas to be acceptable. AEC's calculations were based on much more restrictive load paths. To resolve this issue, LITCO performed detailed finite element analyses on these local areas of the rack. As discussed in Section 5.2 above, plastic analyses were performed which demonstrated that stresses in these areas met the acceptance criteria. 


\subsection{LITCO POSITION ON ACCEPTABILITY OF HOLTEC'S DESIGN}

\subsection{LITCO Comments}

Until late in the project (August 1995), LITCO did not officially perform technical review on the design analysis, contracting instead with AEC to perform this function. LITCO was, however, closely involved with the resolution of comments raised by AEC. During this comment resolution phase of the review, new concerns noted by LITCO were discussed with Holtec and resolved accordingly. These concerns were not officially transmitted as review comments. For example, LITCO recognized that the deep drop of a fuel container into a corner port would locally damage concrete beneath the impacted pedestal, and requested that the pool liner be evaluated for potential rupture. LITCO further recommended that Holtec's puncture evaluation of the liner be supplemented with a calculation where strain levels in the liner are considered. In studying the analysis package, LITCO also noted an error in the strain energy absorption calculation for the rack baseplate when impacted by a fuel container, and recommended an improvement for the fatigue evaluation per ASME Code criteria. LITCO also noted the deficiency in Holtec's original full pool analysis related to the lack of flexibility in the individual racks of the full pool model, recommending that this be improved on in the final analysis. During the comment resolution effort, LITCO also raised numerous questions and comments that helped reshape the documentation for the analysis.

LITCO reviewed the final report primarily for satisfactory resolution of all outstanding issues on the analysis, and performed a technical review of Holtec's final full pool analysis for the racks of Pool 1. LITCO's review of the final report revealed a few editorial difficulties, which were corrected prior to issue of the report. LITCO's review of the full pool analysis is documented in a letter dated November 27, 1995 (Ref. 14). The emphasis of this review was on ensuring that the full pool model adequately reflected properties of the single fuel rack model, and that the simulation was properly implemented and interpreted. Items evaluated were: dynamic properties used for the individual racks within the model, properties used for the interties and pedestals, modeling of the bumpers at the base of the racks, modeling of hydrodynamic effects, time history input, and response of the system.

In the full pool analysis, each rack in the 35-rack array was represented by a simplified model. The model for the basic rack structure consisted of a beam element having 12 degrees of freedom (DOF) and two rattling masses to represent fuel, each having two DOF. The beam stiffnesses for this simplified model were determined by applying unit loads to the detailed single rack finite element model. To verify this 16 DOF beam model, Holtec performed an analysis on a simplified model for just a single rack with interties modeled as they were in the detailed single rack analyses. For this verification, the wetted fuel mass in the simplified model was set equal to the fuel mass of the detailed model. Results from analyses on the two models showed that calculated values for pedestal loads, rack displacements, and intertie loads were comparable, but not exact. Precise comparisons were not expected based on the reduction in degrees of freedom in the simplified model. Thus, the simplified models in the full pool analysis are considered to be reasonably representive of the rack structures. LITCO's review effort revealed that the theoretical basis for the full pool analysis was valid, and that the $6 \times 5$ and $5 \times 5$ racks were correctly placed in the model. There were no technical errors discovered in the implementation of the analysis or in the results obtained. There was general consistency in rack behavior determined for the various load cases considered, and results from the full pool analysis were comparable to those obtained from single rack analysis. Therefore, LITCO's review of the full pool analysis did not identify technical difficulties. LITCO officially transmitted two comments requesting that the final report present (1) a description of the theoretical development of the 
full pool model, and (2) details on results pertaining to contact between the racks at the base. This information was included in the final issue of the report.

\subsection{Assessment of the Review}

An independent review of the design analysis was initiated early in the design effort, when AEC was contracted to perform the essence of the technical review. AEC performed this review function into the final stages of the design effort. Through this duration, AEC was able to review all aspects of the stress analyses and to perform independent analyses on selected topics. AEC furnished numerous review comments in this process, and was involved in the resolution to the majority of these issues. Because of time and budget constraints, LITCO assumed responsibility for completing the review effort late in the analysis process. This meant that LITCO had to reach satisfactory resolution on several major issues identified by AEC, and assure that the final analysis implemented resolutions to these and any other outstanding review comments. To address several of the major issues, Holtec performed a full pool analysis for the racks of Pool 1. Because AEC was not involved at the time that Holtec completed this effort, LITCO performed an independent review of the full pool analysis.

To address one of AEC's major review comments, LITCO performed detailed finite element analyses on the intertie connections for Pool 1 racks. These analyses were independently reviewed within LITCO's organization. In summary, the full spectrum of analyses performed received complete independent review.

\subsection{Adequacy of Holtec's Design Analysis}

Holtec's final analysis package was assessed for acceptability based on whether it met requirements of the Procurement Specification. This document specifies the ASME Code Section III Subsection NF for criteria governing acceptability of stresses. Holtec's analyses indicated that stresses in the racks and associated components met these acceptance criteria for both static and seismic load cases. LITCO supplemented Holtec's analyses with a detailed assessment of the intertie portions of the racks, which verified that stress levels in these portions of the racks were acceptable. In the final analysis, Holtec's approach was to utilize a single rack analysis to perform a detailed assessment on stresses in the rack, and to use full pool analyses to confirm that the detailed single rack analyses were generally bounding analyses for the racks. It is recognized that the approach did not permit a determination of actual stresses in the racks. The complexities involved in performing time history analysis on a system of 35 spent fuel racks connected together and possessing numerous nonlinearities in behavior would prohibit a determination of the actual stresses in the racks (even if the seismic input were a true representation of the actual earthquake). Holtec's approach did provide a practical means for demonstrating compliance with the acceptance criteria and therefore assuring a safe design for the racks.

Numerous comments were generated in an independent review of Holtec's design analysis. These review comments were resolved through an extensive effort that entailed two significant revisions to the original design analysis report and some detailed finite element analysis performed by LITCO. Because satisfactory resolution to these comments has been reached, LITCO finds Holtec's design analysis for the Pool 1 racks to be acceptable. 


\subsection{REFERENCES}

1. Fluor Daniel, Inc., Procurement Specification for Chemical Processing Plant Building 666 FSA Rack Reconfiguration Project, MS1 Fuel Handling Unit (FHU) Storage Racks (Pools 1 and 5), September 14, 1992.

2. Holtec International, Calculation Package for Structural Evaluation of Holtec Spent Fuel Storage Racks for Idaho National Engineering Laboratory Pools 1 and 5, Holtec Report HI-941181, November 1995.

3. American Society of Mechanical Engineers, Boiler \& Pressure Vessel Code, Section III Division 1, Subsection NF, 1992.

4. G. H. Borschel and A. J. Matule, Scope of Work Statement for Independent Review of the Fuel Storage Rack Analysis and Design for the FSA Rack Reconfiguration Project, September 21, 1993.

5. American Society of Mechanical Engineers, Quality Assurance Program Requirements for Nuclear Facilities, ASME NQA-1-1989 Edition, September 15, 1989.

6. W. O. Crownover, LITCO, ltr to A. Mukherjee, Holtec International, Purchase Order No. 222833 - CPP Fuel Racks - Seismic Analysis, WOC-44-95, February 14, 1995.

7. W. O. Crownover, LITCO, Itr to J. R. Bosnik, Holtec International, Purchase Order 222833 - Fuel Rack Seismic Analysis Report, WOC-71-95, March 21, 1995.

8. Lockheed Idaho Technologies Company, Inc., Review Record Form, Form LITCO-5733X (12-89).

9. M. E. Nitzel and R. G. Rahl, Analysis of ICPP Fuel Storage Rack Inner Tie and Corner Tie Substructures, Lockheed Martin Idaho Technologies, INEL-96/0012, Idaho National Engineering Laboratory, January 1996.

10. J. G. Arendts ltr to G. K. Miller, ICPP Pool 1 Fuel Storage Inter-Rack Tie Substructure Analysis Review, JGA-07-95, December 22, 1995.

11. Advanced Engineering Consultants, Holtec Rack Independent Review, telefax dated September 27, 1995.

12. Advanced Engineering Consultants, Independent Review of the Fuel Storage Rack Analysis and Design for the FSA Rack Reconfiguration Project, February 1996.

13. A. I. Soler, Holtec International, ltr to W. O. Crownover, June 5, 1995.

14. J. M. Lacy Itr to G. K. Miller, Review of Holtec's Whole Pool Multi-Rack Seismic Analysis for the ICPP FSA Rack Reconfiguration, JML-44-95, November 27, 1995. 